\title{
Congener diversity, topographic heterogeneity and human- assisted dispersal predict spread rates of alien herpetofauna at a global scale
}

Xuan Liu, ${ }^{1 \dagger}$ Xianping Li, ${ }^{1,2+}$ Zetian Liu, ${ }^{1,2+}$ Reid Tingley, ${ }^{3}$ Fred Kraus, ${ }^{4}$ Zhongwei Guo ${ }^{1}$ and Yiming $\mathrm{Li}^{1}{ }^{\text {* }}$

\begin{abstract}
Understanding the factors that determine rates of range expansion is not only crucial for developing risk assessment schemes and management strategies for invasive species, but also provides important insight into the ability of species to disperse in response to climate change. However, there is little knowledge on why some invasions spread faster than others at large spatiotemporal scales. Here, we examine the effects of human activities, species traits and characteristics of the invaded range on spread rates using a global sample of alien reptile and amphibian introductions. We show that spread rates vary remarkably among invaded locations within a species, and differ across biogeographical realms. Spread rates are positively related to the richness of native congeneric species and human-assisted dispersal in the invaded range but are negatively correlated with topographic heterogeneity. Our findings highlight the importance of environmental characteristics and human-assisted dispersal in developing robust frameworks for predicting species' range shifts.
\end{abstract}

\section{Keywords}

Biological invasion, biotic acceptance hypothesis, climate change, Darwin's naturalisation hypothesis, invasiveness, range shifts, rates of range expansion.

Ecology Letters (2014) 17: 821-829

\section{INTRODUCTION}

Introductions of alien species have increased at exponential rates as a result of economic globalisation (Blackburn \& Duncan 2001; Kraus 2009) and are causing substantial damage to both biodiversity and the economy (Pimentel et al. 2005). Understanding why some alien invasions spread at greater rates than others is not only of fundamental importance for developing robust risk assessment schemes and effective management strategies for invasive species (Hastings et al. 2005; Wilson et al. 2007), but can also provide insight into species' range shifts in response to climate change (Sax et al. 2007; Angert et al. 2011; Sorte et al. 2010). Several studies have analysed the effects of dispersal modes, geographic barriers, habitat corridors and human activities on spread rates of individual alien species at landscape scales (e.g. Tingley et al. 2013; Mari et al. 2014). Population models have also been used to predict spread, but these have generally performed poorly due to highly variable spread rates driven exogenously by environmental heterogeneity or endogenously by demographic or genetic stochasticity (Melbourne \& Hastings 2009). Yet, few studies have compared spread rates among taxa across large spatiotemporal scales or evaluated the relative importance of species traits, environmental characteristics and human activities in determining spread rates.

\footnotetext{
${ }^{1}$ Key Laboratory of Animal Ecology and Conservation Biology, Institute of Zoology, Chinese Academy of Sciences, 1 Beichen West Road, Chaoyang District, Beijing, 100101, China

${ }^{2}$ University of Chinese Academy of Sciences, 19 Yuquan Road, Shijingshan, Beijing, 100039, China
}

Alien species colonisation is influenced by different factors at different stages along the 'introduction-naturalisation-invasion' continuum (Richardson \& Pyšek 2012), and thus it is crucial to separate the variables that are important at different invasion stages. Numerous hypotheses have been proposed to explain introduction outcomes, but results remain largely inconsistent among studies. Many of these hypotheses have been proposed to explain establishment success - the stage of the invasion pathway preceding spread (Blackburn et al. 2011) - but may also be relevant in explaining rates of range expansion. Invasion hypotheses can broadly be grouped into those that consider event-level (e.g. propagule pressure), location-level (e.g. biotic and abiotic environmental characteristics of introduction locations) and species-level (e.g. life-history and ecological traits) parameters (Duncan et al. 2003).

Propagule pressure is a measure of the number of individual organisms introduced to a site, including both the number of distinct release events and the number of individuals released in each event, and it is a key determinant of invasion success (Lockwood et al. 2009; Blackburn et al. 2013). High propagule pressure can facilitate establishment and spread by allowing invaders to overcome demographic stochasticity or genetic bottlenecks following introduction (Lockwood et al. 2009). However, reliable data on introduction efforts are rarely available, and thus many studies have been unable to

\footnotetext{
${ }^{3}$ School of Botany, The University of Melbourne, Melbourne, Vic., 3010, Australia

${ }^{4}$ Department of Ecology and Evolutionary Biology, University of Michigan, Ann Arbor, MI, 48109, USA

*Correspondence: E-mail: liym@ioz.ac.cn

${ }^{+}$First coauthors contributing equally to this work.
} 
accurately control for the effects of propagule pressure on invasion success or have done so only indirectly (e.g. Bomford et al. 2009; Lockwood et al. 2009; Tingley et al. 2011).

Hypotheses pertaining to invasibility of introduction locations emphasise the importance of geographic barriers, human activities, interactions with native species and climatic similarity between a species' native and invaded ranges. Once introduced, invaders are often faced with a multitude of geographic and environmental barriers, such as marine boundaries or inhospitable habitat corridors (Bellemain \& Ricklefs 2008). However, human activities can help invading species overcome these barriers by supplying novel niches (Tingley et al. 2013), eliminating native predators and competitors (Rodda \& Tyrrell 2008), or facilitating long-distance dispersal (Wilson et al. 2009). Conversely, disturbed landscapes tend to have higher hunting pressure, which may limit invasion success for some species by reducing numbers of propagules (Jeschke \& Strayer 2006). Biotic interactions between invaders and the native community may also affect invasion outcomes. Darwin's pre-adaptation hypothesis postulates that invasion success will increase with an alien species' taxonomic similarity to the native community, as shared traits may pre-adapt the alien to the new environment and thus facilitate its invasion (Darwin 1859). Alternatively, Darwin's naturalisation hypothesis predicts that the presence of closely related species at an introduction site will reduce the probability of invader success due to competition with relatives for limited resources (Darwin 1859). The climatic suitability of an introduction site can also influence establishment (Duncan et al. 2001; Bomford et al. 2009; van Wilgen et al. 2009), although invaders can sometimes colonise climates that are unoccupied or unavailable in their native ranges ( $\mathrm{Li}$ et al. in press).

A final set of explanatory hypotheses relates to specieslevel characteristics. Some life-history traits, for example, are correlated with high survival rates and an ability to cope with novel environments, characteristics that are critical in determining invasion success (Blackburn et al. 2009a). Lifehistory characteristics associated with dispersal ability (e.g. body size) or rapid population growth (e.g. early maturity, large clutch size) may be particularly crucial and are frequently used as predictors of spread (Duncan et al. 2001; Forsyth et al. 2004; Allen et al. 2013). Habitat affinities may also be important. Aquatic species have been hypothesised to spread faster than terrestrial species due to their ability to utilise water flow for long-distance dispersal (Grosholz 1996; Sorte et al. 2010), but different aquatic habitats (e.g. lentic vs. lotic) may differ in their ability to foster dispersal. Finally, native range size may be indicative of spread potential, as species with larger ranges may have broader environmental tolerances or greater dispersal abilities (Knapp \& Kuhn 2012).

Here, we conduct the first global-scale analysis of these hypotheses using data on spread rates of alien reptile and amphibian species. Reptiles and amphibians are ideal for this study, as residence times and numbers of introduction events have been recently summarised (Kraus 2009). Furthermore, virtually no measurements of expansion rate for any alien reptile or amphibian species have been published, much less a general analysis of expansion rates. Our study is timely given growing concerns over the negative impacts of invasive reptiles and amphibians on biodiversity and the importance of spread rate in contributing to invasiveness (Kraus 2009; Dorcas et al. 2012). An ability to predict spread rates could allow wildlife managers to ameliorate biodiversity impacts by prioritising species and areas for pre-emptive conservation and management attention.

\section{MATERIALS AND METHODS}

\section{Introduction data}

We collated data on alien reptiles and amphibians from a published database containing information on 2142 introduction events of 676 taxa (Kraus 2009), and we updated the nomenclature using the sources listed in Appendix S1. This database categorised introductions by recipient jurisdiction (i.e. a country, or state/province of USA and Canada, or important biogeographical island group that is part of a larger country). To accurately determine the amount of time that a species has had to spread in a given jurisdiction, we used only introductions that occurred once to a jurisdiction, resulted in establishment and had information on date of establishment and pathway of introduction. Kraus (2009) assigned "1" introduction event to all records known to involve only a single introduction but also as a default value for those records involving a possibly larger but uncertain number of introduction events. We reviewed all relevant literature cited in Kraus (2009) or published subsequently to include in our sample only records that unambiguously involved a single-introduction event.

We used records having either an exact date of introduction or a narrow range of dates comprising 10 years or less (e.g. "late 1940s"). In the latter case, we used the mid-point of the date range as the estimated introduction date. This process resulted in a final database of 201 introduction events (75 events for amphibians, 126 for reptiles) for 107 species (36 amphibians, 71 reptiles) that were introduced to 94 different jurisdictions (Table S1).

\section{Spread rates}

Residence time for each introduction was estimated as the difference between the year of the most recent record (See Tables S1 and S2 for relevant databases and references) and the year of the introduction event (Kraus 2009). We collected speciesoccurrence records during the residence time of each species from the literature and a variety of databases, including GBIF, USGS, DAISIE, NMNH, NCMNS, EUNIS, HerpNET, GISIN and speciesLink (for details see Table S2), and transformed these data into equal-area grid cells with a resolution of $c .10^{\prime}$ (c. $16 \times 16 \mathrm{~km}$ at the equator). Occupied grid cells included any increase in range resulting from expansion outside the jurisdiction of original introduction, so long as no separate introduction events were involved. We then measured mean annual spread rate for each invaded range for each species by dividing the total number of occupied grid cells by the residence time (Hastings et al. 2005). 
The species distribution data used here are the best available but are inevitably influenced by variation in survey effort across regions. Although there is no general method to correct for this limitation without information on survey effort, one might expect sampling bias to be more severe at finer spatial resolutions. We therefore repeated our analyses at the coarser resolution of $30^{\prime}($ c. $50 \times 50 \mathrm{~km}$ at the equator). An insubstantial change in results would suggest that the analyses were relatively robust to sampling bias.

\section{Predictor variables}

Based on the results of previous studies, we hypothesised that the following five types of variables would be correlated with spread rates (see Table S3 for predicted relationships).

(i) Geographic barriers. For each invaded range, we calculated a topographic heterogeneity index by averaging the maximum range in elevation of all 30 arc-second (c. $1 \mathrm{~km}$ at the equator) grid cells within each $10^{\prime}$ cell using data from WorldClim (http://www.worldclim.org/) (Jetz et al. 2009). We also categorised invaded areas as being island (2), mini-continent (1) or mainland (0) in origin, with large islands $\left(\geq 19140 \mathrm{~km}^{2}\right)$ such as Madagascar, New Caledonia, New Zealand and New Guinea regarded as mini-continents using the criterion suggested by Bellemain \& Ricklefs (2008).

(ii) Congeneric species richness. For each invaded range, we determined the number of sympatric native congeners by overlaying GIS range maps produced by the IUCN Global Amphibian Assessment (http://www.iucnredlist.org/amphibians) and IUCN Global Reptile Assessment (http://www.iucnredlistassessments.org/the-global-reptile-assessment/) (Tingley et al. 2011). While a phylogenetic approach to estimating similarity with native species would permit a finer resolution analysis (van Wilgen \& Richardson 2011), such an approach is currently impossible to apply at a global scale due to insufficient phylogenetic resolution among the world's reptile and amphibian species.

(iii) Climatic suitability. We calculated the climatic similarity between each species' native and invaded range using eight climatic variables and an ecological niche modelling method (van Wilgen et al. 2009) (Appendix S2).

(iv) Human influence. We considered three variables reflecting the potential influence of human activities on spread rates. First, we consulted the literature to determine whether human-assisted dispersal within a jurisdiction following the initial introduction event was explicitly mentioned or could be reasonably inferred by disjunct distribution across inhospitable terrain or within a very short time $\operatorname{span}($ confirmed $=1$; unconfirmed $=0)($ Table S4). Second, species have been introduced via multiple pathways (e.g. pet trade, biocontrol, food, cargo stowaway, etc., Kraus 2009). We therefore classified introductions as intentional (1) or unintentional (0) (Kraus 2009) to assess whether the mode of transportation pathway influences spread rates. Finally, we collected data on averaged human population density within each species' invaded range (data available at: http://sedac.ciesin.columbia.edu/gpw) after resampling population data to a $10^{\prime}$ resolution using bilinear interpolation. (v) Species traits and native-range size. For each species, we evaluated effects of species' traits (body size, clutch size, age at maturity, brain size, habitat use and breeding habits) on spread rates. Information on species traits was collected from various publications and databases (Table S1 and S5). Because data on maturation age and brain size were only available for a relatively small subset of species, and we found no relationship between these variables and spread rates (Table S6), we did not include them in our final analyses. We categorised habitat use as "1" for aquatic species (those living predominantly or entirely in water), and "0" for terrestrial species (Table S1). We also included a dichotomous variable describing whether a species breeds (e.g. lays eggs or bears offspring) in lotic waters (slow-moving water, rivers, or streams) or not (lentic water and terrestrial habitats) (Table S1). Native range size was approximated by summing the number of $10^{\prime}$ grid cells occupied within each species' native range (calculated using Hawth's Tools in ArcGIS) (Beyer 2010).

\section{Statistical models of spread rates}

To improve linearity, body size, clutch size and native range size were log transformed, whereas topographic heterogeneity, human population density and congeneric species richness were $\log (\mathrm{x}+1)$ transformed. Generalised linear mixed-effects models (GLMMs) with a Gaussian-error distribution and identity link were used to investigate effects of the 12 predictors on log-transformed spread rates. To account for geographic and taxonomic autocorrelation, invaded biogeographical realm was included as a single random effect, and class, order and species were entered as nested random effects; all other variables were treated as fixed effects (Tingley et al. 2011). The biogeographical realms we considered were: Afrotropics, Australasia, Indo-Malay, Nearctic, Neotropics, Palearctic, Oceania and Madagascar (Hof et al. 2010).

We used multimodel inference based on information theory (Akaike's Information Criterion corrected for small sample sizes, $\mathrm{AIC}_{\mathrm{c}}$ ) to evaluate the relative importance of each predictor (Burnham \& Anderson 2002). Models including all possible combinations of the 12 predictors (total $2^{12}-1=4095$ models) were ranked, and the relative importance of each variable was calculated by summing Akaike weights over all of the models that included that particular variable. We report the top 10 models (with the lowest $\mathrm{AIC}_{\mathrm{c}}$ values) and considered models that were within $2 \mathrm{AIC}$ units (i.e. $\Delta \mathrm{AIC}_{\mathrm{c}} \leq 2$ ) of the top models to be highly supported (Burnham \& Anderson 2002). We conducted all analyses in R v2.15.2 (R Development Core Team 2012), using the lmer function in the lme 4 package (Bates et al. 2013) and the dredge and model.avg functions in the MuMIn package (Barton 2013).

Collinearity between predictors was generally weak: of the 66 pair-wise correlations, only two were above the commonly used threshold of $|r|=0.7$ and none was above the more stringent (but common) threshold of $|\mathrm{r}|=0.85$ (Table S6). Furthermore, collinearity does not affect modelfit statistics such as AIC (although it can cause instability in parameter estimates and standard errors) (Burnham \& Anderson 2002). 
To investigate whether model rankings and variable-importance weights were robust to data uncertainties, we conducted the following sensitivity analyses on the full data set. First, we conducted the analyses at a coarser $30^{\prime}$ resolution to assess sensitivity to geographic variation in survey effort (Table S7A). Second, we excluded introductions to the Indo-Malay region, where there were small sample sizes $(n=8)$ but relatively high spread rates (see Fig. 1) (Table S7B). Finally, we removed 19 introductions (Table S1) that involved long residence times ( $\geq 100$ years) on geographically restricted islands so as to exclude the possibility for potential range saturation in those cases (Table S7C).

\section{RESULTS}

\section{Spread rates of amphibian and reptile invaders}

At a $10^{\prime}$ spatial resolution, invaders occupied an average of 9.0 grid cells (range $=1-133$ ) with a mean residence time of 81.6 years (range $=1-2194$ years, Table S1). On average, invaders spread at a rate of 0.24 grid cells year yed $^{-1}$ (range $=0.01-2.0$ ), and $15.9 \%$ of invaders colonised $\geq 0.5$ grid cells year ${ }^{-1}$ (Table S1 and Fig. 1). Spread rates varied remarkably among invaded locations within a species (Table $\mathrm{S} 1)$. For example, the 12 measured invasions for Rhinella marina expanded at a rate ranging from 0.03 to 0.61 grid cells year ${ }^{-1}$. Similarly, 11 Lithobates catesbeianus and 14 Ramphotyphlops braminus invasions resulted in the colonisation of $0.02-0.8$ and $0.01-1.0$ grid cells year ${ }^{-1}$ respectively. Trachemys scripta elegans in South Carolina, USA spread at
1.5 grid cells year ${ }^{-1}$, the fastest among reptiles, whereas Scinax cuspidatus colonised 2.0 grid cells year ${ }^{-1}$ in Minas Gerais, Southeastern Brazil, the fastest among amphibians (Table S1).

Spread rates differed among biogeographical realms (Kruskal-Wallis test, $\chi^{2}=30.5$, d.f. $=7, P<0.001$ ), with the highest spread rates observed in the Indo-Malay region $(N=8)$, followed by Nearctic $(N=40)$, Australasia $(N=10)$, Neotropics $(N=72)$, Oceania $(N=39)$, Palearctic $(N=24)$, Afrotropics $(N=2)$ and Madagascar $(N=6)$ (Fig. 1 and Fig. 2a). When the four biographical realms (Indo-Malay, Australasia, Afrotropics and Madagascar) with a low sample size $(N<11)$ were excluded, the remaining, better sampled realms (Nearctic, Palearctic, Neotropics and Oceania) still showed differences in spread rates $\left(\chi^{2}=13.3, \quad\right.$ d.f. $\left.=3, \quad P=0.004\right)$. However, there were no differences in spread rates among different taxonomic orders for the entire database $\left(\chi^{2}=4.9\right.$, d.f. $=4, P=0.30)$ (Fig. 2b).

\section{Correlates of spread rates}

After controlling for geographic and taxonomic autocorrelation, the top 10 models included eight predictor variables (Table 1). However, the two most highly supported models (i.e. $\left.\Delta \mathrm{AIC}_{\mathrm{c}} \leq 2\right)$ only contained three variables: native congeneric species richness, human-assisted dispersal and topographic heterogeneity. In these two models, fixed factors explained $11-15 \%$ of the variation in spread rates $\left(R_{\text {marginal }}^{2}\right)$, whereas the combination of fixed factors and geographic and taxonomic random effects explained $45-46 \%$ of the variation

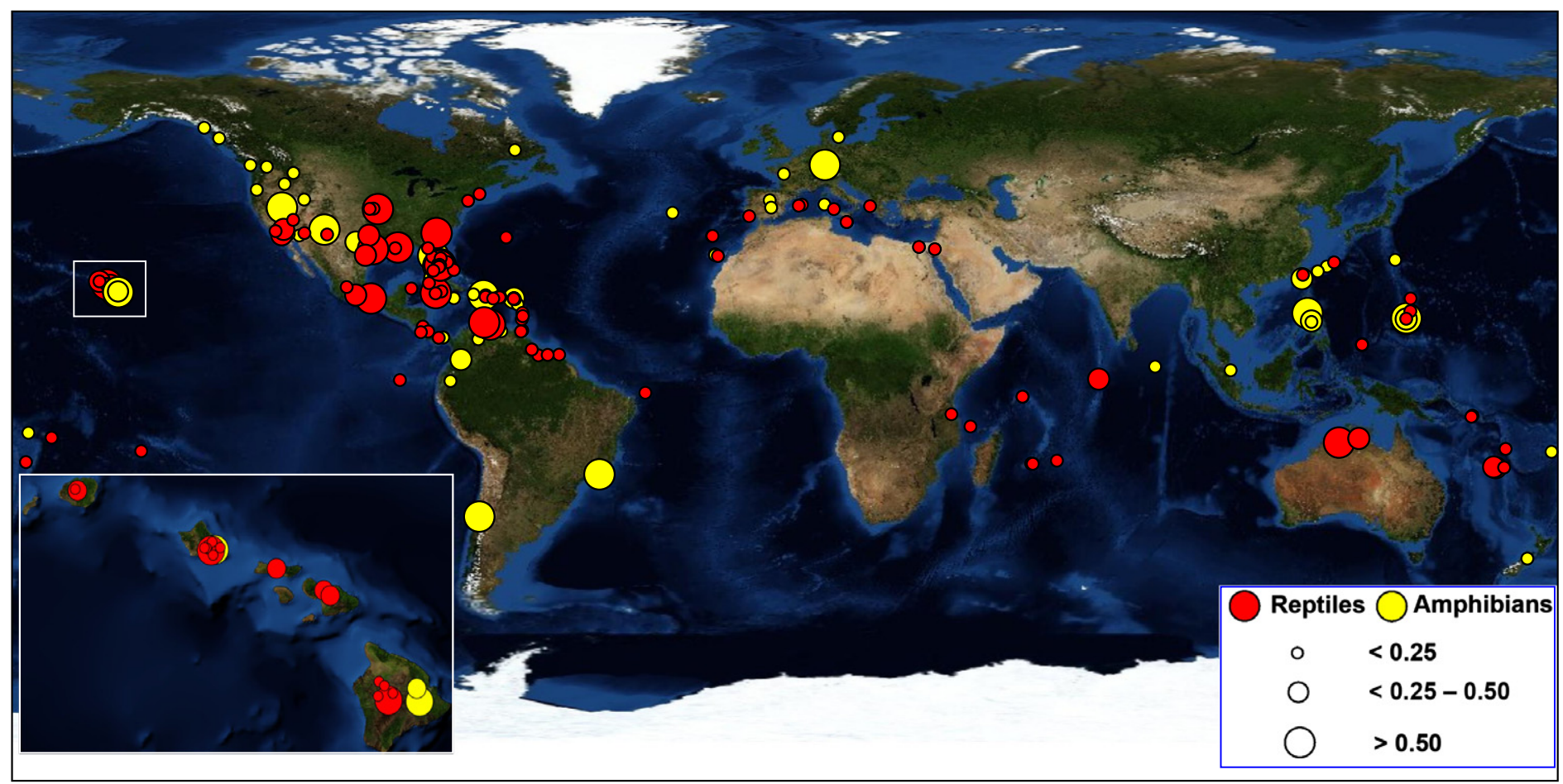

Figure 1 Spread rates of the 201 invasions used in this study. The locations are based on the mid-point coordinates of the invaded grid cells on mainland areas, and on the island with the largest number of grid cells on invaded islands. Circle size is proportional to spread rate (grid cells year ${ }^{-1}$ ). Hawaii is magnified in the inset. 

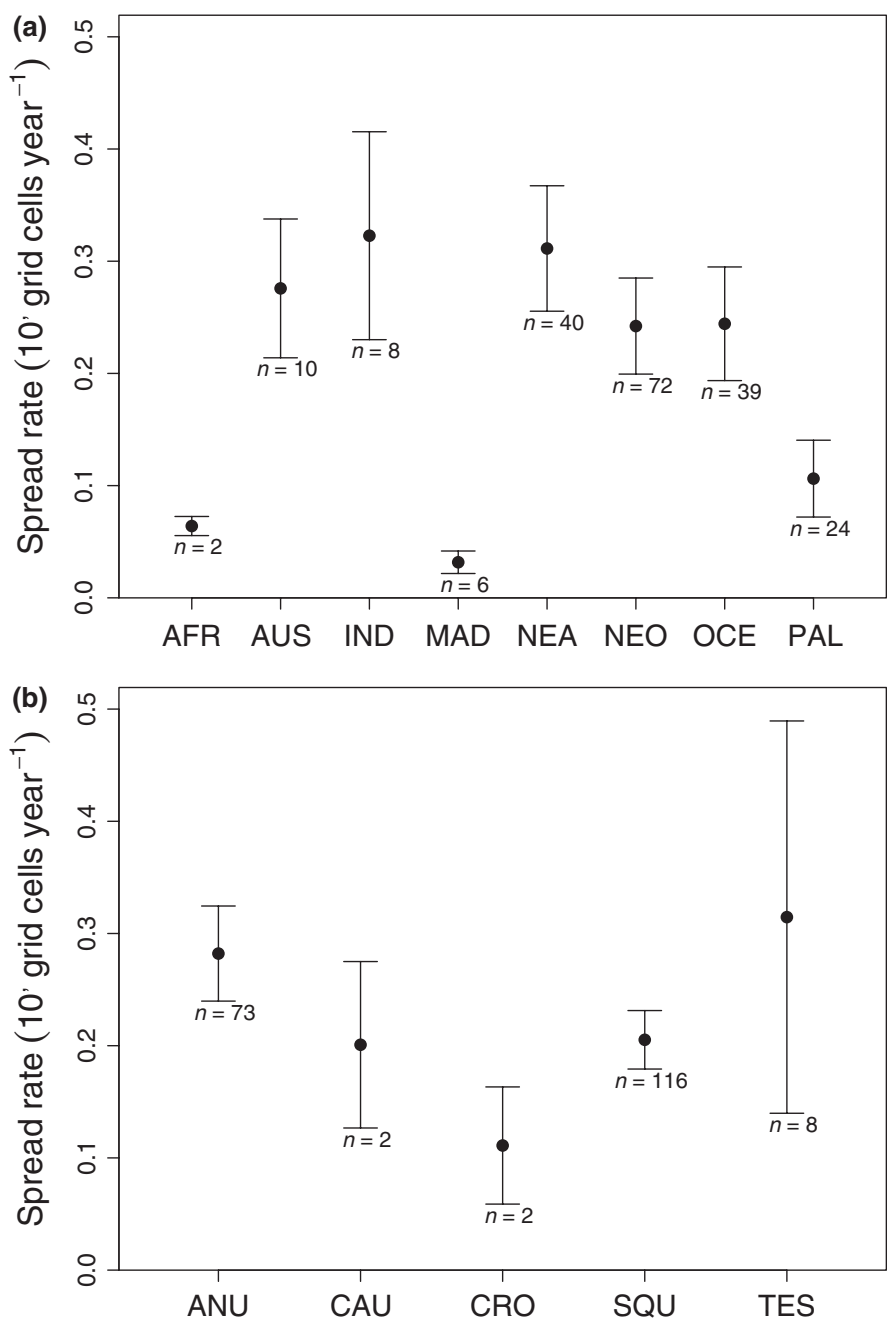

Figure 2 Mean spread rates ( \pm SE) of 201 invasions among (a) eight biogeographical realms (AFR, Afrotropics; AUS, Australasia; IND, IndoMalay; MAD, Madagascar; NEA, Nearctic; NEO, Neotropics; PAL, Palaearctic; OCE, Oceania), and (b) among five taxonomic orders (ANU, Anura; CAU, Caudata; CRO, Crocodylia; SQU, Squamata; TES, Testudines).

$\left(R_{\text {conditional }}^{2}\right)$ (Table 1$)$. There was moderate model selection uncertainty across models (e.g. $W_{i}=0.26$ and 0.16 for the two top models, Table 1), and thus we used multimodel inference to investigate the effects of each predictor.

These analyses revealed that native congeneric species richness (relative importance value $=0.92$ ), human-assisted dispersal (0.90) and topographic heterogeneity (0.60) were the most important predictors of spread rates (Table 2); modelaveraged $95 \%$ confidence intervals for these three variables also excluded zero. Spread rates were positively related to congeneric species richness and human-assisted dispersal but were significantly lower when species were introduced to areas with greater topographic heterogeneity (Table 2). Other species-, event- and location-level predictors had comparatively minor effects (relative importance values ranged from 0.04 to 0.15 , Table 2).

Highly supported models and variable importance rankings were similar when spread rates were analysed at a coarser $30^{\prime}$ resolution (Table $\mathrm{S} 7 \mathrm{~A}$ ). In addition, sample outliers did not significantly affect which models were most highly supported, and we obtained similar explanatory power when we removed the eight introductions to the Indo-Malay region (i.e. those with the highest spread rates but lowest sample size) (Table S7B) or when we excluded the 19 introductions that involved long residence times ( $\geq 100$ years) in geographically restricted areas (Table S7C).

\section{DISCUSSION}

This study is the first to quantify the relative importance of biotic and abiotic characteristics, species traits and anthropogenic factors in determining spread rates of alien species at a global scale. Using historical records of reptile and amphibian introductions, we have shown that spread rates increase with increasing richness of native congeneric species and with subsequent human-assisted dispersal, but that spread is significantly slower in areas with heterogeneous terrain. Thus, spread rates are a function of human-mediated dispersal subsequent to the initial introduction and biotic and abiotic environmental characteristics of the invaded location.

The positive relationship between spread rates and native congeneric species richness observed here suggests that closely related species do not competitively exclude invaders. The most plausible explanation for this finding is that congeneric species respond similar to available resources and abiotic conditions, and the presence of multiple close relatives signifies environments conducive to spread (the 'pre-adaptation hypothesis'; Darwin 1859; Tingley et al. 2011). This finding accords with the results of previous global studies of establishment success in both amphibians (Tingley et al. 2011) and reptiles (Ferreira et al. 2012). Numbers of established reptiles and amphibians were also found to be positively related to native species richness in Europe, and the same was evident for reptiles in North America (Poessel et al. 2012). In contrast, studies of amphibian and reptile introductions to Florida, USA, have produced mixed results. For example, Allen et al. found no effect of congener presence on establishment success of herpetofauna (Allen et al. 2013), whereas van Wilgen \& Richardson (2011) found a negative relationship between phylogenetic distance and establishment success. Importantly, the only previous study to investigate correlates of spread in alien herpetofauna found a negative effect of congener presence (Allen et al. 2013), although that study did not measure rates of spread because of insufficient data on residence times. Our results therefore provide the first support for the pre-adaptation hypothesis in explaining spread rates of biological invasions.

The strong influence of human-assisted dispersal revealed by our analyses corroborates both field observations and recent molecular evidence that human-assisted dispersal has facilitated the spread of individual alien herpetofauna (Kraus 2009; Chapple et al. 2013). Human-assisted dispersal has played an especially critical role in determining spread rates for many species that have been introduced to archipelagos. For example, 20 of 24 species introduced to Hawaii spread to multiple islands (Table S4, Fig. 1). The dispersal of the large majority of these species among islands was due to human 
Table 1 The top ten generalised linear mixed-effects models (GLMMs) investigating the effects of invader traits, human activities and biotic and abiotic characteristics on spread rates of alien herpetofauna

\begin{tabular}{|c|c|c|c|c|c|c|c|c|c|c|c|}
\hline & 1 & 2 & 3 & 4 & 5 & 6 & 7 & 8 & 9 & 10 & $R^{2}$ \\
\hline Native congener richness & - & - & - & & • & • & - & • & • & • & 0.08 \\
\hline Human-assisted dispersal & - & - & - & • & $\bullet$ & - & • & & • & - & 0.04 \\
\hline Topographic heterogeneity & - & & - & • & • & • & & & • & • & 0.02 \\
\hline Insularity & & & & - & & & & & & - & 0.06 \\
\hline Climate match & & & - & & & & $\cdot$ & & & & $0.5 \times 10^{-4}$ \\
\hline Breeding habits (lotic or not) & & & & & - & & & & & & 0.001 \\
\hline Habitats (aquatic or not) & & & & & & • & & & & & 0.01 \\
\hline Body size & & & & & & & & & - & & $0.1 \times 10^{-4}$ \\
\hline Pathway mode intentional & & & & & & & & & & & $0.2 \times 10^{-3}$ \\
\hline Clutch size & & & & & & & & & & & 0.006 \\
\hline Native geographic range size & & & & & & & & & & & $0.1 \times 10^{-5}$ \\
\hline Human population density & & & & & & & & & & & 0.004 \\
\hline $\begin{array}{l}\text { Biogeographical realm and } \\
\text { taxonomic random effect }\end{array}$ & $\cdot$ & $\cdot$ & $\cdot$ & $\cdot$ & $\cdot$ & $\bullet$ & • & $\cdot$ & $\cdot$ & • & 0.33 \\
\hline$\Delta \mathrm{AIC}$ & 0 & 1.0 & 3.9 & 4.2 & 4.4 & 4.6 & 4.8 & 4.9 & 5.0 & 5.2 & - \\
\hline $\mathrm{AIC}_{\mathrm{c}}$ & 305.3 & 306.3 & 309.2 & 309.5 & 309.7 & 309.9 & 310.1 & 310.2 & 310.3 & 310.5 & - \\
\hline $\mathrm{W}_{\mathrm{i}}$ & 0.26 & 0.16 & 0.04 & 0.03 & 0.03 & 0.03 & 0.02 & 0.02 & 0.02 & 0.02 & - \\
\hline$R_{\text {marginal }}^{2}$ & 0.15 & 0.11 & 0.15 & 0.14 & 0.15 & 0.15 & 0.11 & 0.08 & 0.15 & 0.16 & - \\
\hline$R_{\text {conditional }}^{2}$ & 0.45 & 0.46 & 0.45 & 0.37 & 0.46 & 0.45 & 0.46 & 0.40 & 0.45 & 0.44 & - \\
\hline
\end{tabular}

- Indicates that a variable is included in the model; $\triangle \mathrm{AIC}$, the difference between each model and the highest ranked model; $\mathrm{AIC}_{\mathrm{c}}$, Akaike's information criterion adjusted for small sample sizes; $\mathrm{W}_{\mathrm{i}}$ (Akaike weights), the probability that a model is best given the particular set of models considered; $R^{2}$ marginal,

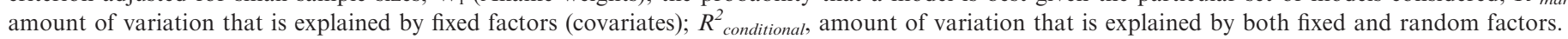
Models include invaded biogeographical realm as a random effect and taxonomic class, order and species as nested random effects. Models are ranked in order of increasing $\mathrm{AIC}_{\mathrm{c}} \cdot R^{2}$ is the deviance explained by each factor based on single-variable and null (random effect only) GLMMs.

Table 2 Results of model averaging based on GLMMs (4095 models) using invader traits, human activities and biotic and abiotic characteristics to explain spread rates of alien herpetofauna

\begin{tabular}{|c|c|c|c|c|}
\hline Variables & $\beta$ & SE & $\begin{array}{l}95 \% \text { CI } \\
\text { (lower, upper) }\end{array}$ & $\begin{array}{l}\text { Relative } \\
\text { importance }\end{array}$ \\
\hline Native congener richness & 0.25 & 0.07 & $0.11,0.39$ & 0.92 \\
\hline Human-assisted dispersal & 0.25 & 0.07 & $0.10,0.39$ & 0.90 \\
\hline Topographic heterogeneity & -0.15 & 0.06 & $-0.27,-0.04$ & 0.60 \\
\hline Insularity & -0.11 & 0.07 & $-0.24,0.02$ & 0.15 \\
\hline Climate match & 0.03 & 0.18 & $-0.32,0.37$ & 0.13 \\
\hline $\begin{array}{l}\text { Breeding habits (lotic } \\
\text { or not) }\end{array}$ & 0.05 & 0.13 & $-0.21,0.31$ & 0.10 \\
\hline $\begin{array}{l}\text { Habitats (aquatic } \\
\text { or not) }\end{array}$ & 0.09 & 0.10 & $-0.10,0.29$ & 0.10 \\
\hline Body size & -0.01 & 0.10 & $-0.22,0.19$ & 0.08 \\
\hline $\begin{array}{l}\text { Pathway mode } \\
\text { intentional }\end{array}$ & -0.03 & 0.08 & $-0.18,0.13$ & 0.06 \\
\hline $\begin{array}{l}\text { Native geographic } \\
\text { range size }\end{array}$ & 0.0002 & 0.05 & $-0.09,0.09$ & 0.04 \\
\hline Clutch size & 0.02 & 0.05 & $-0.08,0.12$ & 0.04 \\
\hline $\begin{array}{l}\text { Human population } \\
\text { density }\end{array}$ & -0.01 & 0.04 & $-0.09,0.08$ & 0.04 \\
\hline
\end{tabular}

Model-averaged $95 \%$ confidence intervals that do not overlap zero are shown in bold. $\beta$ : model-averaged regression coefficients.

activities because they cannot disperse across marine barriers without human assistance.

Our analyses revealed relatively weak evidence for effects of human population density and pathway mode (intentional vs. accidental) on spread rates. High human populations create disturbed habitats which may contain resources that facilitate establishment or promote transportation opportunities for fur- ther spread (Rodda \& Tyrrell 2008; Wilson et al. 2009), but hunting pressure might also be higher in densely populated areas (Jeschke \& Strayer 2006; Li et al. 2006), reducing likelihood of establishment and spread of alien species. Pathway of introduction clearly affects likelihood of successful establishment (Kraus 2009; Rago et al. 2012); however, we found no effect of this variable on spread rates, potentially because both intentional and unintentional pathways can involve additional long-distance dispersal by humans. However, further studies on the importance of human behaviour variables in assisting spread of invasive species are warranted as our pathway-mode variable is only a single crude measure.

Dispersal rates also depend on an invader's inherent ability to negotiate terrain without human assistance, but there is debate on the role of topographic barriers in determining the range size of native species (Baselga et al. 2012). The negative relationship observed here between spread rates and topographic heterogeneity demonstrates that topographic barriers can slow range expansion of alien species. Marine boundaries also impose constraints on dispersal for most reptile and amphibian species, but insularity per se only had weak effects on spread rates in our analyses (Tables 1 and 2). This may be due to human-assisted dispersal breaching those marine barriers previously preventing spread (e.g. facilitating spread among Hawaii islands, as noted above).

Geographical differences in native congeneric species richness, human-assisted dispersal and topographic heterogeneity should thus partly explain the differences in spread rates we identified among biogeographical realms. For example, among the four biogeographical realms with the largest sample sizes, the higher spread rates observed in the Nearctic compared to the Palearctic might partly be due to the higher native conge- 
neric species richness and lower topographic heterogeneity in the former set of introduction sites (Table S8B-E). In contrast, spread rates in the Neotropics and Oceania are identical, suggesting that the lower congeneric richness and higher topographic heterogeneity of the former are offset by the importance of human-assisted dispersal therein (Table S8B-E). However, differences in spread rates across all biogeographical realms (Fig. 2a) must be interpreted with greater caution as sample sizes in some realms are extremely low.

Overall, our findings suggest that the factors promoting establishment success among alien reptiles and amphibians are not necessarily the same as those promoting spread. For example, previous studies have found that climate match (Bomford et al. 2009; van Wilgen et al. 2009; Fujisaki et al. 2010; van Wilgen \& Richardson 2012), native geographic range size (Allen et al. 2013; but see counter-example in Bomford et al. 2009) and introduction pathway (Rago et al. 2012) predict the probability of successful establishment, but these factors generally had negligible effects on spread rates in our analyses. Earlier studies of herpetofauna (Allen et al. 2013), mammals (Forsyth et al. 2004) and birds (Duncan et al. 2001) found that smaller species colonise larger geographic ranges. Conversely, larger amphibian and reptile species are more likely to be introduced by humans (Tingley et al. 2010; van Wilgen et al. 2010). However, we found no evidence that body size was associated with spread rates. Similar to a prior study that detected no difference in spread rates between terrestrial and marine invaders (Grosholz 1996), we found little effect of aquatic living or breeding habits on spread rates. This may reflect the limited connectivity among aquatic habitats at coarse spatial scales or that our variables did not adequately capture the diversity of relationships between aquatic herpetofauna and aquatic habitats (Mari et al. 2014).

Interestingly, although the relationships we detected accord with theory and intuition, taxonomic and geographic random effects explained substantial proportions (c. $30 \%$ in the two highly supported models) of the variation in spread rates (Table 1). One potential explanation for the strong effect of taxonomy is that our models were missing important traits that are taxonomically shared. However, we considered five species-level traits (native-range size, aquatic habitat use, lotic breeding habits, body size and clutch size) that have compelling theoretical links with spread rates and are important determinants of establishment and spread in other taxonomic groups, and found no effects of these traits in our analyses. Alternatively, strong effects of taxonomy and geography may reflect variation in introduction effort among taxonomic groups and regions (Blackburn \& Duncan 2001). We were able to partially control for effects of propagule number by including only single-introduction events in our analysis; however, due to data unavailability, we were unable to control for numbers of animals released in each introduction event, and this may have been partially captured by the taxonomic and geographic random effects in our models. Data on propagule sizes may be relevant for explaining additional variation in spread rates, but these data are absent for the large majority of herpetofaunal introductions, and we doubt that this limitation can readily be corrected. Possibly, other taxa may be more amenable to investigating the importance of this factor.
Our results from herpetofaunal invasions have important implications for the development of risk assessment schemes for invasive species. The effects on spread rates of geographical barriers, subsequent human-assisted dispersal and attributes of the native community at the introduction site suggest that invasion success is to a large extent a biogeographical and social, rather than a strictly ecological phenomenon. Thus, for established populations of alien reptiles and amphibians, rather than focusing on species-level traits, efforts to minimise spread might instead focus on locations that host multiple native congeneric species and have low topographic heterogeneity, as these areas are more likely to promote invasions. Our finding that human-assisted dispersal is a strong predictor of spread rates demonstrates that management efforts also need to reduce the probability of subsequent spread by humans following initial introduction, which further highlights the importance of research into the psychological and sociological factors that foster introductions (Kraus 2009).

Range expansions of alien species and climate-induced range shifts of native species both result from dispersal of organisms across large spatial scales (Sax et al. 2007; Sorte et al. 2010). Therefore, understanding factors that influence dispersal rates of species may be crucial for predicting species' range changes. We found little contribution of species-level traits to spread rates of alien species, echoing the results of a large-scale study that evaluated the effects of multiple species traits on climate-induced range shifts in native North American birds and mammals, British odonates and Swiss alpine plants (Angert et al. 2011). These findings imply that species-level traits may be poor predictors of range shifts for both native and alien species. Whether topographic heterogeneity and native congener richness - which we have identified as important for alien reptiles and amphibians - also impact dispersal of native species tracking climate change, remains to be explored. Comparisons between these two fields may reveal important insights into the characteristics that allow both native and non-native species to rapidly shift their geographic ranges (Sorte et al. 2010).

\section{ACKNOWLEDGEMENTS}

We are grateful to five anonymous referees who provided insightful and constructive comments which have greatly improved the manuscript. Funding was provided by the National Science Foundation of China (31370545 and 31200416). RT was supported by the Australian Research Council (ARC) Centre of Excellence for Environmental Decisions.

\section{AUTHORSHIP}

YL and XLIU designed the study, XL, ZLIU, XLIU, FK and RT collected the data, XLIU, YL, XL, ZG and RT analysed the data, XLIU, RT, FK and YL wrote the manuscript.

\section{REFERENCES}

Allen, C.R., Nemec, K.T., Wardwell, D.A., Hoffman, J.D., Brust, M., Decker, K.L. et al. (2013). Predictors of regional establishment success 
and spread of introduced non-indigenous vertebrates. Global Ecol. Biogeogr., 22, 889-899.

Angert, A.L., Crozier, L.G., Rissler, L.J., Gilman, S.E., Tewksbury, J.J. \& Chunco, A.J. (2011). Do species' traits predict recent shifts at expanding range edges? Ecol. Lett., 14, 677-689.

Bartoń, K. (2013). MuMIn: Multi-model inference. R package version 1.9.0. Available at: http://CRAN.R-project.org/package $=$ MuMIn. Last accessed 25 January 2014.

Baselga, A., Lobo, J.M., Svenning, J.C. \& Araujo, M.B. (2012). Global patterns in the shape of species geographical ranges reveal range determinants. J. Biogeogr., 39, 760-771.

Bates, D., Maechler, M. \& Bolker, B. (2013). lme4: Linear mixed-effects models using S4 classes, R package, version 0.999999-0, 2012. Available at: http://CRAN. R-project. org/package $=1$ me4. Last accessed 25 January 2014.

Bellemain, E. \& Ricklefs, R.E. (2008). Are islands the end of the colonization road?. Trends Ecol. Evol., 23, 461-468.

Beyer, H. (2010). Hawth's analysis tools for ArcGIS. 2004. Available at: http:// spatialecology.com/htools. Last accessed 20 November 2013.

Blackburn, T.M. \& Duncan, R.P. (2001). Determinants of establishment success in introduced birds. Nature, 414, 195-197.

Blackburn, T.M., Cassey, P. \& Lockwood, J.L. (2009a). The role of species traits in the establishment success of exotic birds. Global Change Biol., 15, 2852-2860.

Blackburn, T.M., Pyšek, P., Bacher, S., Carlton, J.T., Duncan, R.P., Jarošík, V. et al. (2011). A proposed unified framework for biological invasions. Trends Ecol. Evol., 26, 333-339.

Blackburn, T.M., Prowse, T.A.A., Lockwood, J.L. \& Cassey, P. (2013). Propagule pressure as a driver of establishment success in deliberately introduced exotic species: fact or artefact?. Biol. Invasions, 15, 1459-1469.

Bomford, M., Kraus, F., Barry, S.C. \& Lawrence, E. (2009). Predicting establishment success for alien reptiles and amphibians: a role for climate matching. Biol. Invasions, 11, 713-724.

Burnham, K. \& Anderson, D. (2002). Model Selection and Multimodel Inference: A Practical Information-Theoretic Approach, 2nd edn. Springer-Verlag, New York.

Chapple, D.G., Whitaker, A.H., Chapple, S.N.J., Miller, K.A. \& Thompson, M.B. (2013). Biosecurity interceptions of an invasive lizard: origin of stowaways and human-assisted spread within New Zealand. Evol. Appl., 6, 324-339.

Darwin, C. (1859). On the Origin of Species London. John Murray, London.

Dorcas, M.E., Willson, J.D., Reed, R.N., Snow, R.W., Rochford, M.R., Miller, M.A. et al. (2012). Severe mammal declines coincide with proliferation of invasive Burmese pythons in Everglades National Park. Proc. Natl Acad. Sci., 109, 2418-2422.

Duncan, R.P., Bomford, M., Forsyth, D.M. \& Conibear, L. (2001). High predictability in introduction outcomes and the geographical range size of introduced Australian birds: a role for climate. J. Anim. Ecol., 70, 621-632.

Duncan, R.P., Blackburn, T.M. \& Sol, D. (2003). The ecology of bird introductions. Annu. Rev. Ecol. Evol. S., 34, 71-98.

Ferreira, R.B., Beard, K.H., Peterson, S.L., Poessel, S.A. \& Callahan, C.M. (2012). Establishment of introduced reptiles increases with the presence and richness of native congeners. Amphibia-Reptilia, 33, 387-392.

Forsyth, D.M., Duncan, R.P., Bomford, M. \& Moore, G. (2004). Climatic suitability, life-history traits, introduction effort, and the establishment and spread of introduced mammals in Australia. Conserv. Biol., 18, 557-569.

Fujisaki, I., Hart, K.M., Mazzotti, F.J., Rice, K.G., Snow, S. \& Rochford, M. (2010). Risk assessment of potential invasiveness of exotic reptiles imported to south Florida. Biol. Invasions, 12, 2585-2596.

Grosholz, E.D. (1996). Contrasting rates of spread for introduced species in terrestrial and marine systems. Ecology, 77, 1680-1686.

Hastings, A., Cuddington, K., Davies, K.F., Dugaw, C.J., Elmendorf, S., Freestone, A. et al. (2005). The spatial spread of invasions: new developments in theory and evidence. Ecol. Lett., 8, 91-101.
Hof, C., Rahbek, C. \& Araujo, M.B. (2010). Phylogenetic signals in the climatic niches of the world's amphibians. Ecography, 33, 242250

Jeschke, J.M. \& Strayer, D.L. (2006). Determinants of vertebrate invasion success in Europe and North America. Global Change Biol., 12, 16081619.

Jetz, W., Kreft, H., Ceballos, G. \& Mutke, J. (2009). Global associations between terrestrial producer and vertebrate consumer diversity. Proc. Biol. Sci., 276, 269-278.

Knapp, S. \& Kuhn, I. (2012). Origin matters: widely distributed native and non-native species benefit from different functional traits. Ecol. Lett., 15, 696-703.

Kraus, F. (2009). Alien Reptiles and Amphibians: A Scientific Compendium and Analysis. Springer, Dordrecht.

Li, Y.M., Wu, Z.J. \& Duncan, R.P. (2006). Why islands are easier to invade: human influences on bullfrog invasion in the Zhoushan archipelago and neighboring mainland China. Oecologia, 148, 129-136.

Li, Y.M., Liu, X., Li, X.P., Petitpierre, B. \& Guisan, A. (in press). Residence time, expansion toward the equator in the invaded range and native range size matter to climatic niche shifts in non-native species. Global Ecol. Biogeogr., DOI: 10.1111/geb.12191.

Lockwood, J.L., Cassey, P. \& Blackburn, T.M. (2009). The more you introduce the more you get: the role of colonization pressure and propagule pressure in invasion ecology. Divers. Distrib., 15, 904-910.

Mari, L., Casagrandi, R., Bertuzzo, E., Rinaldo, A. \& Gatto, M. (2014). Metapopulation persistence and species spread in river networks. Ecol. Lett., 17, 426-434.

Melbourne, B.A. \& Hastings, A. (2009). Highly variable spread rates in replicated biological invasions: fundamental limits to predictability. Science, 325, 1536-1539.

Pimentel, D., Zuniga, R. \& Morrison, D. (2005). Update on the environmental and economic costs associated with alien-invasive species in the United States. Ecol. Econ., 52, 273-288.

Poessel, S.A., Beard, K.H., Callahan, C.M., Ferreira, R.B. \& Stevenson, E.T. (2012). Biotic acceptance in introduced amphibians and reptiles in Europe and North America. Global Ecol. Biogeogr., 22, 192-201.

R Development Core Team (2012). R: A Language and Environment for Statistical Computing. R Foundation for Statistical Computing, Vienna, Austria. ISBN 3-900051-07-0. Available at: http://www. R-project.org/.

Rago, A., While, G.M. \& Uller, T. (2012). Introduction pathway and climate trump ecology and life history as predictors of establishment success in alien frogs and toads. Ecol. Evol., 2, 1437-1445.

Richardson, D.M. \& Pyšek, P. (2012). Naturalization of introduced plants: ecological drivers of biogeographical patterns. New Phytol., 196, 383-396.

Rodda, G.H. \& Tyrrell, C.L. (2008). Introduced species that invade and species that thrive in town: are these two groups cut from the same cloth. In: Urban Herpetology (ed. Mitchell, J.C., Jung Brown, R.E. \& Bartholomew, B.). SSAR Herpetological Conservation, Salt Lake City, Utah, pp. 327-341.

Sax, D.F., Stachowicz, J.J., Brown, J.H., Bruno, J.F., Dawson, M.N., Gaines, S.D. et al. (2007). Ecological and evolutionary insights from species invasions. Trends Ecol. Evol., 22, 465-471.

Sorte, C.J.B., Williams, S.L. \& Carlton, J.T. (2010). Marine range shifts and species introductions: comparative spread rates and community impacts. Global Ecol. Biogeogr., 19, 303-316.

Tingley, R., Romagosa, C.M., Kraus, F., Bickford, D., Phillips, B.L. \& Shine, R. (2010). The frog filter: amphibian introduction bias driven by taxonomy, body size and biogeography. Global Ecol. Biogeogr., 19, 496-503.

Tingley, R., Phillips, B.L. \& Shine, R. (2011). Establishment success of introduced amphibians increases in the presence of congeneric species. Am. Nat., 177, 382-388.

Tingley, R., Phillips, B.L., Letnic, M., Brown, G.P., Shine, R. \& Baird, S.J.E. (2013). Identifying optimal barriers to halt the invasion of cane toads Rhinella marina in arid Australia. J. Appl. Ecol., 50, 129-137. 
van Wilgen, N.J. \& Richardson, D.M. (2011). Is phylogenetic relatedness to native species important for the establishment of reptiles introduced to California and Florida? Divers. Distrib., 17, 172-181.

van Wilgen, N.J. \& Richardson, D.M. (2012). The roles of climate, phylogenetic relatedness, introduction effort, and reproductive traits in the establishment of non-native reptiles and amphibians. Conserv. Biol., 26, 267-277.

van Wilgen, N.J., Roura-Pascual, N. \& Richardson, D.M. (2009). A quantitative climate-match score for risk-assessment screening of reptile and amphibian introductions. Environ. Manage., 44, 590-607.

van Wilgen, N., Wilson, J., Elith, J., Wintle, B. \& Richardson, D. (2010). Alien invaders and reptile traders: what drives the live animal trade in South Africa? Anim. Conserv., 13, 24-32.

Wilson, J.R.U., Richardson, D.M., Rouget, M., Procheş, Ş., Amis, M.A., Henderson, L. et al. (2007). Residence time and potential range: crucial considerations in modelling plant invasions. Divers. Distrib., 13, $11-22$.
Wilson, J.R.U., Dormontt, E.E., Prentis, P.J., Lowe, A.J. \& Richardson, D.M. (2009). Something in the way you move: dispersal pathways affect invasion success. Trends Ecol. Evol., 24, 136-144.

\section{SUPPORTING INFORMATION}

Additional Supporting Information may be downloaded via the online version of this article at Wiley Online Library (www.ecologyletters.com).

\section{Editor, Hector Arita}

Manuscript received 23 December 2013

First decision made 29 January 2014

Manuscript accepted 25 March 2014 